\title{
Examining the Effects of Domestic versus Global Prices Uncertainty on Sectoral Price Inflation in Malaysia
}

\author{
Eng Woo Chiew and Siok Kun Sek* \\ School of Mathematical Sciences, Universiti Sains Malaysia \\ 11800 Minden, Penang, Malaysia \\ *Corresponding author: sksek@usm.my
}

Article history

Received: 10 November 2019

Received in revised form: 21 November 2019

Accepted: 19 December 2019

Published online: 31 December 2019

\begin{abstract}
Price stability is one of the main policy objectives that is targeted by policymakers in many countries. Price uncertainty occurs due to the changes in market structure and consumer preference and expectation, which may affect price stability. In this study, the researchers aimed to examine the effects of price uncertainty of consumer price disaggregation in Malaysian sectors. To be specific, the researchers were seeking to discover on how domestic and global commodity prices can affect sectoral Consumer Price Index (CPI) on price inflation in Malaysia and most importantly, whether the effect is different for economic sectors in Malaysia. In addition, the effects of other factors (i.e., internal and external factors) on Malaysian sectoral CPI inflation were also studied. The threshold generalized autoregressive conditional heteroscedasticity (TGARCH) model was used to generate the price uncertainties. For the purpose of analysis, the threshold regression approach was applied based on time series of each single sector, followed by a combination of panel data of all sectors. The results differed across sectors, revealing that the impact of price uncertainties was determined by the sensitivity of each sector towards the price uncertainties. The effect of price increase is larger than the effect of price decrease. Price fluctuations were obvious in sectors that were dependent on consumer price or commodity price. Exchange rate and oil price inflation had also greatly influenced the CPI inflation.
\end{abstract}

Keywords Consumer price; threshold regression; price uncertainty; panel data; commodity price.

Mathematics Subject Classification 62J02, 91B84

\section{Introduction}

Price stability is the main concern of policymakers as inflation rate may reflect the economic performance and well-being of an economy. Over-fluctuation in price level may lead to uncertainties in price expectation of investors, producers, and consumers; hence, this may affect 
their decisions for investment and influences the market demand and supply. Such uncertainties may cause instability of production, trading, and investment, which will eventually lead to a negative impact on economic performance.

Malaysia has experienced volatility in domestic price inflation, especially in the 1970s and 1980s due to the significant increase in the global energy and food prices that was triggered by disruptions in supply, rapid growth of domestic aggregate demand, and sharp increases in import prices [1]. The inflation rate in Malaysia is shown in Figure 1. The highest spike in inflation can be seen in 1973 to 1974, whereby the inflation peaked up to $17.3 \%$ due to the abrupt increment in oil price during that period. From 1980 to 1981, the inflation peaked up again to $9.7 \%$. The spike in the global commodity was not limited to the oil and energy sector alone, but also extended to the global food prices due to shortages of food supplies, the drop in raw materials caused by bad weather conditions ([2], [3]). From 1985 to 1986, Malaysia has experienced a period of very low inflation at the height of economic recession. The low inflation was caused by the tight liquidity position and moderate increment in demand as the outcome of increased under-utilization of the plants capacity and manpower. During the high economic growth from 1988 to 1996, Malaysia was able to maintain the inflation rate in the range of $2 \%$ to $5 \%$. During these periods, the inflation was mainly affected by another global oil price crisis due to the Gulf War in 1990, lack of food supply, and increase in bus and taxi fares [4].

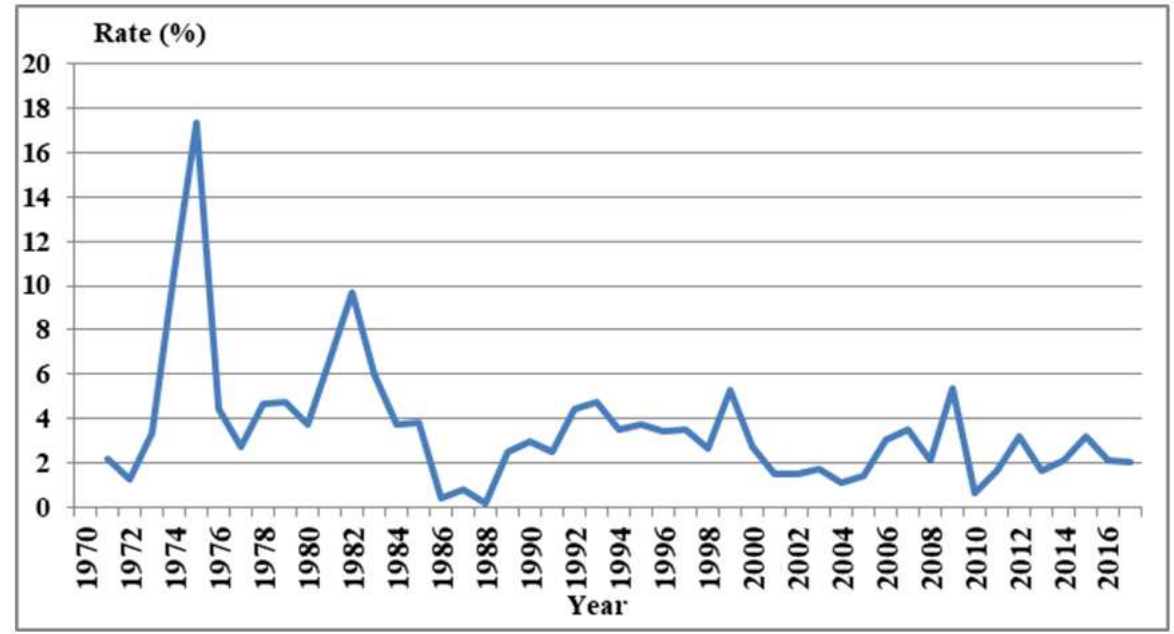

Figure 1: Inflation in Malaysia from 1970 to 2016

(Source: Sketched by author based on the data from Department of Statistics Malaysia)

The 1997 and 1998 Asian financial crisis triggered another greater impact on the inflation rate. The inflation rate in Malaysia increased from $2.7 \%$ to $5.3 \%$ due to the depreciation of Malaysian Ringgit . Malaysian Ringgit reached a depreciation rate of about $28.2 \%$ against the US Dollar during the end of 1997. This was followed by the increment in interest rates, fuel prices, and prices of goods and services. Another factor which contributed to higher inflation in 1998 was the cyclical shortage of essential food items. This phenomenon reflected the increase on cost pressures that resulted from higher import prices ([5], [6]).

In the early 2000s, Malaysia experienced moderate to very low inflation rates after gaining its momentum from the crisis. The inflation started to increase again in 2005, reaching its peak in July 2008 at 8.5\%, and it was driven mainly by the higher global commodity and food prices, 
followed by the global oil price shock in 2008. The increase in global commodity prices was caused by the higher demand associated with speculative activity in the commodity markets. The limited agricultural land allocations and global warming had strained the global supply of commodities. On the other hand, higher food price was explained by the global shortage of essential supplies of rice and wheat ([1], [6]).

After the global oil shock in 2008, the inflation returned to its stable level until 2016. The inflation rates were maintained in the range of $1 \%$ to $4 \%$. In 2011 , the inflation rate exhibited a moderate pace from $1.7 \%$ to $3.2 \%$. The inflation movement was affected by the surge in commodity price in 2011 and also the rise in food commodities prices, especially the global corn price due to disruption in supply and low stockpiles [6].

The historical data and research reports revealed that the price movement in Malaysia was highly affected by external price changes, in particular the commodity prices. However, to what extent the influences of external prices had on domestic prices is explained by how much sensitive each sector is to external price changes. Unfortunately, studies that examine inflation in different sectors are lacking. Therefore, this study attempts to fill this gap by examining the CPI inflation and using the sectoral data. Our main objective is to reveal the main factors that determine CPI inflation in different sectors of consumer goods in Malaysia. In particular, the researchers compared the effects of domestic against global price uncertainties of the sectoral CPI inflation in Malaysia. The threshold regression was applied to detect the effects of structural threshold. The results revealed that three inflation uncertainties, which were consumer price price index uncertainties (CPIu), producer price index uncertainties (PPIu), and commodity price uncertainties $(\mathrm{CPu})$ can either have direct or indirect impact on $\mathrm{CPI}$ inflation of Malaysia. However, the results varied across sectors and regimes. Besides, exchange rate and oil price inflation also appeared to be the main determinant factors.

The remaining sections of this paper are organised as follows: Section 2 discusses the literature review theoretically and empirically ; Section 3 explains the data and methodology; Section 4 summarises the results; and the last section concludes on the findings.

\section{Review of Literature}

\subsection{Theoretical Framework}

\subsubsection{The Relationship between CPI and PPI}

The relation between PPI and CPI can be explained by using two different approaches, namely supply and demand. The supply approach, production chain is linked with CPI and PPI, whereby raw materials are used as inputs in the production of intermediate products. The intermediate products will then be used in the production of final products. Changes in the price of raw materials will affect the price of intermediate products and final products, which will ultimately affect consumer prices [7]. The demand approach, changes in demand for consumer goods affect the input of production costs. Production costs reflect the opportunity cost of intermediate products and resources, which will reflect the demand for final products and services [8].

According to Anggraeni and Irawan [8], it was assumed that demand for primary goods

depends on future consumer price expectations. This assumption indicated that current demand 
and expectations of current demand in the past determined the consumer prices, and future demand expectations determined the producer prices. Demand for final products had an impact on input prices, and therefore, this suggested that CPI affected PPI.

\subsubsection{The Relationship between Commodity Prices and CPI}

The global commodity prices are among the key drivers of domestic inflation to Malaysia. However, the transmission of global commodity prices to inflation is however influenced by the government's administered price mechanism. Domestic prices of essential commodities, such as rice, sugar, and fuel are administered or subsidised by the government. Hence, the degree of adjustments to administer prices in response to changes in global commodity prices would be a key determinant of the ultimate impact on inflation [9].

Blomberg and Harris [10] discussed the relation between commodity prices and CPI. Contrary to conventional theory, there is no long-run link between the level of commodity prices and the level of consumer prices. Although commodity and consumer prices tend to diverge over time, commodity price levels and consumer price inflation tend to move together over time, that is, they are co-integrated. Commodities have significant predictive power in explaining shortrun movements in CPI inflation, even when the information contained in monetary aggregates, real output, interest rates, and exchange rates were controlled.

\subsubsection{Transmission of Exchange Rate Pass-through (ERPT) to the Inflation}

Exchange rate pass-through can have both direct and indirect effects on consumer prices. The direct effects work through two main channels of transmission. First, prices of imported finished goods become more expensive as a result of the reduced purchasing power of a country's currency. Second, the inputs that are imported and used in the domestic production also become more expensive. Expensive imported inputs leads to higher production costs of domestic producers who may subsequently pass on these higher costs through varying degrees to consumers via higher prices.

The indirect effects of ERPT on consumer prices are transmitted through changes in the levels of aggregate demand and wages, and also in the composition of demand. The depreciation of a domestic currency tends to increase the demand (home and abroad) on goods. Depreciation of a domestic currency implies that imported goods are more expensive and domestic goods (exported goods) are cheaper, causing the shift of demands on domestic goods. When the demand on domestic goods is higher, the additional pressures on domestic prices will lead to a higher demand for labour, and thus induces increase in wages, which in turn could also be reflected in higher prices ([11], [12]).

\subsubsection{The Impact of Inflation Uncertainty on Inflation}

Inflation uncertainty is considered as one of the major costs of inflation. This is because inflation uncertainty not only distorts decisions regarding future saving and investment (due to lower predictability of the real value of future nominal payments), but it also extends the adverse effect of these distortions to the efficiency of resource allocation and level of real activity [13].

The consequences of inflation uncertainty are divided into ex-ante and ex-post consequences. Ex-ante consequences are primary-based decisions in which an economic agent rationally 
anticipates future inflation, and its transmission can be performed via three different channels, namely financial riskier, decision variables like interest rate, and productive versus protective strategies. Ex-post effects of inflation uncertainty include the transfer of wealth due to the undervaluation or overvaluation of real payments against nominal payments which disturbs the status quo between employer and employee, and lender and borrower ([13], [14]).

The monetary policy can also explain the relation between inflation uncertainty and inflation. Explanation on why inflation uncertainty increases with inflation becomes more difficult when the cost of inflation uncertainty is relatively easy to identify. The most appealing explanation involves the response of monetary policy to inflation. When the inflation is low, monetary policymakers try to keep the inflation uncertainty low. To the extent they are successful, inflation remains low and stable. Monetary policymakers are more likely to adopt disinflationary policies during the high inflation. These policies, by lowering the inflation rate, increase inflation variability. Moreover, the policies create inflation uncertainty because the timing and short-run impact of policy on inflation are uncertain [15].

\section{$2.2 \quad$ Empirical Findings}

Many studies have been conducted to examine the determinants of domestic inflation in many countries. However, the impacts were found to vary across sectors and countries.

Many studies have also been conducted to examine the determinants of inflation in Malaysia. Empirical literature showed that dollar appreciation led to lower inflation ([4], [16]). On the other hand, a study by Islam et al. [4] and Murdipi and Law [3] showed that gross domestic product (GDP) and industrial production index (IPI) led to higher domestic inflation. A study of Islam et al. [4] validated the theory of Phillips curve, whereby higher unemployment rate led to lower inflation. Besides, a study by Murdipi and Law [3] revealed that money supply and import prices were also significant determinants of domestic inflation in the long-run, implying that the long-run of higher price phenomenon was due to the demand-pull inflation and international transmission .

Applying data of different countries, previous studies revealed different determinants for inflation. Ruzima and Veerachamy [17] found that agriculture output and import of goods and services were the strong drivers of inflation in Rwanda. The findings also proved that foreign direct investment had positive, but insignificant impact on inflation, while government spending had negative insignificant impacts on inflation. Hassan et al. [18] suggested that exchange rate was the main determinant of inflation in Pakistan in the long-run and short-run. The increase in exports had exacerbated the supply-demand gap which triggered inflation in Pakistan, and thus they suggested that more focus should be put on meeting domestic demand and using resources wisely to boost production. Correlation analysis performed by Kiganda et al. [19] revealed a weak significant association between re-exports and inflation, but a strong significant correlation between domestic exports and inflation in Kenya. The Johansen co-integration test showed that domestic exports had highly influenced the inflation in Kenya, whereby they had a significant positive long-run relation. Another finding from the error correction model (ECM) method showed that the increase in 'broad money supply', depreciation of the rupee and increase in public wages had induced higher inflation in the long-run and short-run [20]. Enu and Havi [21] conducted a co-integration test and found that the higher population and service output had caused higher inflation due to the excess aggregate demand and higher service production 
cost. The aggregate supply should be increased to overcome the excess aggregate demand. The foreign direct investment and foreign aid also had impacts on inflation, but the impacts were opposite with population and service outputs.

There were also a number of studies that focused on oil price pass-through effects on inflation. Sek [22] examined the asymmetric oil price effects on the sectoral inflation in Malaysia. The oil price changes have symmetric and asymmetric effects in oil-intensive sectors (i.e., fuel, manufacturing, transport) in the long run, and the higher oil price had led to higher inflation. Sek [23] found that oil price had a large and influential impact on CPI inflation through the indirect channel (input cost channel) which pass-through into the wholesale price index (WPI) and finally affect CPI inflation. The main determinant of CPI inflation through direct effect is WPI and GDP and they had contributed to higher inflation in the long run for both oil exporting and oil importing countries. Sek et al. [24] used the panel autoregressive distributed lag (ARDL) model to study the effects of oil price changes on the inflation of low oil and high oil dependency countries. Results revealed that the long-run oil price changes had direct effect on domestic inflation in low oil dependency group, but the impact was indirect in determining the domestic inflation in high oil dependency group. Higher oil price induced to higher exporter production cost had passed through into domestic price levels and indirectly increased domestic inflation. As compared to the relative effects with other shocks, the main determinants of domestic inflation were real exchange rate and exporter production cost (high oil dependency group) and domestic output and exporter production cost (low oil dependency group).

There were also a few studies related to the global commodity prices and inflation. An empirical result by Chuah et al. [25] showed that higher global commodity and global food prices had caused higher inflation in Malaysia, whereby the dominant effect came from commodity prices. Rasasi et al. [26], who focused their analysis in Saudi Arabia reported a result that was very much similar with the Malaysian orientation. The non-fuel commodities, namely non-fuel and food prices had more impacts on domestic consumer prices than energy prices (i.e., global commodity, energy, and oil prices) in which the impacts of non-fuel commodity were twice the impacts of energy prices.

The connection between inflation and inflation uncertainty has also been studied previously. Moradi [27] and Daniela et al. [28] used the Granger causality test to test the FriedmanBall hypothesis (inflation Granger-cause the inflation uncertainty) and Cukierman-Meltzer hypothesis (inflation uncertainty Granger-cause the inflation). Both studies showed that Friedman-Ball hypothesis held for all tested countries, while Cukierman-Meltzer hypothesis only held for certain countries.

\section{Data and Methodology}

\subsection{Data}

In this study, the analysis was focused on nine major sectors price indices that were listed in the Consumer Price Index (CPI) in Malaysia. Data on these sectoral price indices were collected from the Department of Statistics Malaysia. The main independent variables of this study were the domestic consumer price index, domestic producer price index, and global commodity price index as well as their price uncertainties. The data of domestic price indices were collected from the Department of Statistics Malaysia, while the data of global commodity price index 
was collected from the World Bank. The data of three price uncertainties were generated from the TGARCH model that will be discussed in the next section. The other independent variables of this study are real effective exchange rate (REER), Dubai Fateh international oil price (US\$ per barrel), and interest rate. The data of oil price were collected from the Federal Reserve Economic Data (FRED) Datastream, while the data of REER and interest rates were collected from the Thomson Reuters Datastream.

The time series data presented in annual format were from 1980 to 2016 for a sample size of 37 years within the year range of 1980 to 2016 for a sample size of 37 years. The panel data were also presented in annual format with 9 cross-sections, ranging from year 1980 to 2016 for each cross-section and for a sample size of 333 observations. For consistency reason, all variables were determined in the form of the natural logarithm. The variables descriptions for sectoral CPI indices are shown in Table 1, while the variable descriptions for independent variables are shown in Table 2.

Table 1: Variable Descriptions for Sectoral CPI and PPI Indices (Natural log form)

\begin{tabular}{|c|l|}
\hline Variables & Description \\
\hline$L C P I B E V$ & CPI for alcoholic beverages and tobacco sector \\
\hline$L C P I C L O T H$ & CPI for clothing and footwear sector \\
\hline$L C P I F O O D$ & CPI for food and non-alcoholic beverages sector \\
\hline$L C P I F U R N$ & CPI for furniture, furnishings and housing equipment sector \\
\hline$L C P I M E D$ & CPI for medical and health sector \\
\hline$L C P I M I S C$ & CPI for miscellaneous goods and services sector \\
\hline$L C P I P O W$ & CPI for power (gross rent, fuel and power) sector \\
\hline$L C P I R E C$ & CPI for recreation, entertainment, education and cultural services sector \\
\hline$L C P I T R A N$ & CPI for transport and communication sector \\
\hline$L C P I s$ & CPI sectoral inflation (panel data) \\
\hline
\end{tabular}

Table 2: Variable Descriptions for independent variables (Natural log form)

\begin{tabular}{|c|l|}
\hline Variables & \multicolumn{1}{c|}{ Description } \\
\hline$L C P I$ & Domestic Consumer Price Index \\
\hline$L P P I$ & Domestic Producer Price Index \\
\hline$L C P$ & Global commodity price index \\
\hline$L C P I u$ & CPI inflation uncertainty \\
\hline$L P P I u$ & PPI inflation uncertainty \\
\hline$L C P u$ & Global CP inflation uncertainty \\
\hline$L O I L$ & Dubai Fateh international oil price \\
\hline$L I N T$ & Interest rate \\
\hline$L R E E R$ & Real effective exchange rate (US\$) \\
\hline
\end{tabular}




\subsection{Methodology}

This study employs two approaches to analyse the data, which were time series analysis and panel data analysis. The analyses involved the following steps and they are shown in the flowchart in Figure 2.

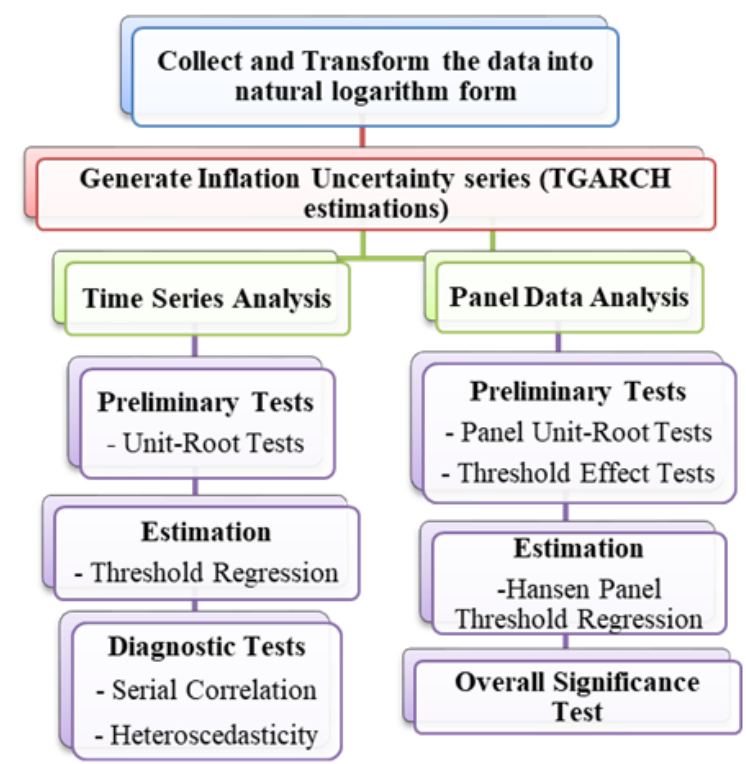

Figure 2: Flowchart of Analysis for This Study

\subsubsection{Time Series Analysis}

This study applies the threshold regression analysis to analyze the indirect and direct effects of price inflation and price uncertainties to the sectoral inflation in Malaysia. Prior to the estimation, the unit-root tests are applied to check the stationarity of the data. This step is followed by conducting the TGARCH model to generate the uncertainties series. The uncertainties series, together with the other data/ variables will then use to perform the threshold regression estimation. The diagnostic tests on the residuals will be applied to check the presence of serial correlation and heteroscedasticity.

\subsubsection{TGARCH Models}

The Generalized Autoregressive Conditional Heteroscedasticity (GARCH) family models are best to use for capturing the volatility or uncertainty. The ARCH model was first developed by Engle [29] to capture the short-run volatility. However, Bollerslev [30] extends the ARCH model by including the Autoregressive (AR) component to capture the long-run volatility and the extended model is named as Generalized ARCH (GARCH) model.

In economic or financial perspectives, the news effect is also one of the factors that influence the volatility. A Threshold GARCH (TGARCH) model which treats differently the bad-good news was proposed by Zakoian [31] to allow the conditional standard deviation to depend upon the sign of the lagged innovations. Glosten et al. [32] introduced the GJR-GARCH model, 
which is the extended idea of Zakoian by defining the conditional variance as a linear piecewise function.

In this study, a TGARCH model is used to examine the volatility and news effects of the domestic CPI, domestic PPI and global commodity price inflation. Also, the uncertainty series of inflation can be generated from the TGARCH model by generating the GARCH variance series for each model. The TGARCH models are estimated based on the following mean equations and variance equation.

\section{Mean equations:}

(a) CPI inflation uncertainty:

$$
\Delta L C P I_{t}=\alpha_{0}+\alpha_{1} \Delta L C P I_{t-1}+\alpha_{2} \Delta L P P I_{t}+\alpha_{3} \Delta L C P_{t}+\varepsilon_{t}
$$

(b) PPI inflation uncertainty:

$$
\Delta L P P I_{t}=\alpha_{0}+\alpha_{1} \Delta L P P I_{t-1}+\alpha_{2} \Delta L C P I_{t}+\alpha_{3} \Delta L C P_{t}+\varepsilon_{t}
$$

(c) CP inflation uncertainty:

$$
\Delta L C P_{t}=\alpha_{0}+\alpha_{1} \Delta L C P_{t-1}+\alpha_{2} \Delta L O I L_{t}+\varepsilon_{t}
$$

\section{Variance equations (TGARCH $(1,1)$ estimation):}

$$
\sigma_{t}^{2}=\alpha_{0}+\beta_{1} \sigma_{t-1}^{2}+\lambda_{1} I_{t-1} \varepsilon_{t-1}^{2}+\alpha_{1} \varepsilon_{t-1}^{2}
$$

where

$$
I_{t-1}=\left\{\begin{array}{l}
1, \varepsilon_{t-1}<0 \text { (good news) } \\
0, \varepsilon_{t-1} \geq 0 \text { (bad news) }
\end{array}\right.
$$

is the threshold variable, $\sigma_{t-1}^{2}$ is the long-run volatility and $\varepsilon_{t-1}^{2}$ is the short-run volatility.

The variance equation is only estimated with both lag 1 for parsimonious reason. If the coefficient of $\lambda_{1} \neq 0$, this implies that the volatility has asymmetry on inflation uncertainty. If the value of $\lambda_{j}>0$, it means that bad news would have a more powerful effect on volatility than good news $([33],[34])$. The effect of $\varepsilon_{t-1}^{2}$ on the conditional variance $\sigma_{t}^{2}$ will depend on whether or not $\varepsilon_{t-1}$ is above or below the threshold [35].

1. If $\varepsilon_{t-1}>0$, then the total effects are given by $\alpha_{1} \varepsilon_{t-1}^{2}$.

2. If $\varepsilon_{t-1}<0$, then the total effects are given by $\left(\alpha_{1}+\lambda_{1}\right) \varepsilon_{t-1}^{2}$.

\subsubsection{Threshold Regression models}

The threshold regression model was introduced to describes a simple form of nonlinear regression featuring piecewise linear specifications and regime switching that occurs when an observed variable crosses unknown thresholds. A standard multiple linear regression model with $N$ observations and $m$ potential thresholds will producing $m+1$ regimes. 
The regressors are divided into two groups, which are the threshold regressors (the variables that are depending on the threshold variables and regime-specific) and non-threshold regressors (the variables that are not depending on the threshold variables and do not vary across regimes). The threshold regression specification with $r$ non-threshold regressors and $p$ threshold regressors in the regime $j$ is given by Kourtellos et al. [36]:

$$
y_{t}=\boldsymbol{\beta}^{\prime} \mathbf{X}_{\mathbf{t}}+\sum_{j=1}^{m+1} I_{j}\left(q_{t}\right) \boldsymbol{\varphi}^{\prime}{ }_{\mathbf{j}} \mathbf{Z}_{\mathbf{t}}+\varepsilon_{t}
$$

where $\boldsymbol{\beta}$ is a $(r \times 1)$ coefficient vector of the non-threshold regressors; $\mathbf{X}_{\mathbf{t}}$ is a $(r \times 1)$ vector of the non-threshold regressors; $\varphi_{\mathbf{j}}$ is a $(p \times 1)$ coefficient vector of the threshold regressors at regime $j$ and $\mathbf{Z}_{\mathbf{t}}$ is a $(p \times 1)$ vector of the threshold regressors.

Suppose that there is an observable threshold variable $q_{t}$ and strictly increasing threshold values (7). Thus, we are in regime $j$ if the value of the threshold variable is at least as large as the $j$-th threshold value, but not as large as the $(j+1)$-th threshold. The threshold value with $j$-th regime is defined as in (8):

$$
\begin{aligned}
& \gamma_{1}<\gamma_{2}<\ldots<\gamma_{m} \\
& q_{t}(j)=\left\{\begin{array}{l}
q_{t}(j)<\gamma_{1}, \mathrm{j}=1 \\
\gamma_{j-1} \leq q_{t}(j)<\gamma_{j}, j=2,3, \ldots, m \\
q_{t}(j) \geq \gamma_{m}, \mathrm{j}=m+1
\end{array}\right.
\end{aligned}
$$

In this study, the maximum number of thresholds that is considered is 2 . We will assign a number of variables as threshold variables, and the best variable will be chosen based on the sequential specification and the number of thresholds will also be detected. The threshold regression specification with single threshold and double thresholds are defined as follows in structural and alternative way [36]:

\section{Single Threshold (Two regimes model):}

(a) Structural:

$$
\Delta y_{t}=\boldsymbol{\beta}^{\prime} \mathbf{X}_{\mathbf{t}}+I\left(q_{t}<\gamma\right) \boldsymbol{\varphi}^{\prime}{ }_{1} \mathbf{Z}_{\mathbf{t}}+I\left(q_{t} \geq \gamma\right) \boldsymbol{\varphi}^{\prime}{ }_{2} \mathbf{Z}_{\mathbf{t}}+\varepsilon_{t}
$$

(b) Alternative:

$$
\begin{aligned}
& \Delta y_{t}=\boldsymbol{\beta}^{\prime} \mathbf{X}_{\mathbf{t}}+\boldsymbol{\varphi}^{\prime}{ }_{1} \mathbf{Z}_{\mathbf{t}}+\varepsilon_{t}, q_{t}<\gamma \\
& \Delta y_{t}=\boldsymbol{\beta}^{\prime} \mathbf{X}_{\mathbf{t}}+\boldsymbol{\varphi}^{\prime}{ }_{2} \mathbf{Z}_{\mathbf{t}}+\varepsilon_{t}, q_{t} \geq \gamma
\end{aligned}
$$

\section{Double Thresholds (Three regimes model):}

(a) Structural:

$$
\Delta y_{t}=\boldsymbol{\beta}^{\prime} \mathbf{X}_{\mathbf{t}}+I\left(q_{t}<\gamma_{1}\right) \boldsymbol{\varphi}^{\prime}{ }_{1} \mathbf{Z}_{\mathbf{t}}+I\left(\gamma_{1} \leq q_{t}<\gamma_{2}\right) \boldsymbol{\varphi}_{2}^{\prime} \mathbf{Z}_{\mathbf{t}}+I\left(q_{t} \geq \gamma_{2}\right) \boldsymbol{\varphi}^{\prime}{ }_{3} \mathbf{Z}_{\mathbf{t}}+\varepsilon_{t}
$$

(b) Alternative:

$$
\begin{aligned}
\Delta y_{t} & =\boldsymbol{\beta}^{\prime} \mathbf{X}_{\mathbf{t}}+\boldsymbol{\varphi}^{\prime}{ }_{1} \mathbf{Z}_{\mathbf{t}}+\varepsilon_{t}, q_{t}<\gamma_{1} \\
\Delta y_{t} & =\beta^{\prime} \mathbf{X}_{\mathbf{t}}+\boldsymbol{\varphi}^{\prime}{ }_{2} \mathbf{Z}_{\mathbf{t}}+\varepsilon_{t}, \gamma_{1} \leq q_{t}<\gamma_{2} \\
\Delta y_{t} & =\boldsymbol{\beta}^{\prime} \mathbf{X}_{\mathbf{t}}+\boldsymbol{\varphi}^{\prime}{ }_{3} \mathbf{Z}_{\mathbf{t}}+\varepsilon_{t}, q_{t} \geq \gamma_{2}
\end{aligned}
$$


where $I()=$. the indicator function.

In this study, we will define $\Delta y_{t}$ as the 9 sectoral inflation, where $y_{t}$ is the sectoral price indices that defined in Table $1 ; \boldsymbol{\beta}^{\prime}=\left[\beta_{1}, \beta_{2}, \beta_{3}\right]$ as the vector of coefficients of non-threshold regressors; $\varphi_{\mathbf{j}}^{\prime}=\left[\varphi_{j 0}, \varphi_{j 1}, \varphi_{j 2}, \varphi_{j 3}\right]$ as the vector of coefficients of threshold regressors at regime $j$ and $\mathbf{X}_{\mathbf{t}}^{\prime}=\left[\Delta L R E E R_{t}, \Delta L O I L_{t}, \Delta L I N T_{t}\right]$ as the vector of non-threshold variables.

We will define two sets of threshold variables and threshold regressors and the set of variables that produce better results will be chosen. If $\mathbf{Z}_{\mathbf{t}}^{\prime}=\left[1, \Delta L C P I_{t}, \Delta L P P I_{t}, \Delta L C P_{t}\right]$, then $q_{t}=$ $\left(\triangle L C P I u_{t}, \triangle L P P I u_{t}, \Delta L C P u_{t}\right)$ or vice versa, where $\mathbf{Z}_{\mathbf{t}}$ is the vector of threshold regressors and $q_{t}$ is the list of threshold variables (the best one will be chosen).

\subsubsection{Panel Data Analysis}

This study applies the Hansen panel threshold regression analysis to analyze the indirect or direct effect of price inflations and price uncertainties to the panel sectoral inflation in Malaysia. Prior to the estimation, the panel unit-root tests are applied to check the stationarity of the data. After the unit-root tests, the threshold effect test is conducted to check whether threshold effect exists in the panel data analysis. Then, the analysis of Hansen panel threshold regression will be conducted and interpreted. Finally, the global F-test will be conducted to check the overall significance of the estimated models.

\subsubsection{Threshold Effect Test}

The threshold effect test is proposed by Hansen [37] to test whether threshold effect exists. If the threshold effect does not exist, then the model is only a linear regression model. We will test the threshold effect based on single threshold effect and double thresholds effect. For single threshold effect, the threshold effect is tested based on the threshold equation (19) [37], [38]. The hypotheses of the single threshold effect are:

$$
\begin{aligned}
& H_{0}: \boldsymbol{\varphi}_{\mathbf{1}}=\boldsymbol{\varphi}_{\mathbf{2}} \text { No threshold effect/ the model is linear) } \\
& H_{1}: \boldsymbol{\varphi}_{\mathbf{1}} \neq \boldsymbol{\varphi}_{\mathbf{2}} \text { (There is a single threshold effect.) }
\end{aligned}
$$

The test statistic has an F-distribution defined as follows:

$$
F_{1}=\frac{\left(S_{0}-S_{1}(\widehat{\gamma})\right)}{\widehat{\sigma}_{1}^{2}}
$$

where

$$
\widehat{\sigma}_{1}^{2}=\frac{S_{1}(\widehat{\gamma})}{N(T-1)}
$$

$S_{0}$ is the error sum of square of the linear model, $S_{1}(\widehat{\gamma})$ is the error sum of square of the single threshold model and $\widehat{\sigma}_{1}^{2}$ is the variance estimates of the single threshold model.

For double threshold effect, the threshold effect is tested based on the threshold equation (21). The hypotheses of the double threshold effect are:

$$
\begin{aligned}
& H_{0}: \boldsymbol{\varphi}_{1}=\boldsymbol{\varphi}_{2}=\boldsymbol{\varphi}_{3} \text { (No threshold effect/ the model is linear) } \\
& H_{1}: \boldsymbol{\varphi}_{\mathbf{1}} \neq \boldsymbol{\varphi}_{\mathbf{2}} \neq \boldsymbol{\varphi}_{3} \text { (There is a double threshold effect) }
\end{aligned}
$$


The test statistic has an F-distribution defined as follows:

$$
F_{2}=\frac{\left(S_{1}\left(\widehat{\gamma}_{1}\right)-S_{2}^{\Gamma}\left(\widehat{\gamma}_{2}^{\Gamma}\right)\right)}{\widehat{\sigma}_{22}^{2}}
$$

where

$$
\widehat{\sigma}_{22}^{2}=\frac{S_{2}^{\Gamma}\left(\widehat{\gamma}_{2}^{\Gamma}\right)}{N(T-1)}
$$

$S_{1}(\widehat{\gamma})$ is the error sum of square of the single threshold model, $S_{2}^{\Gamma}\left(\widehat{\gamma}_{2}^{\Gamma}\right)$ is the error sum of square of the second threshold of double threshold model and $\widehat{\sigma}_{22}^{2}$ is the variance estimates of the second threshold of double threshold model. Bootstrap procedure is used to approximate the critical values of the F-statistic to test the significance of the threshold effect. The rejection of the null hypothesis can be determined by using the $p$-value approach. The null hypothesis if rejected if the $p$-value is smaller than the desired significance level.

\subsubsection{Hansen Panel Threshold Regression analysis}

The Panel Threshold Regression model was introduced by Hansen [37] to describes a simple form of nonlinear panel regression featuring piecewise linear specifications and regime switching that occurs when an observed variable crosses unknown thresholds for a balanced panel. Similar to time series threshold regression, the standard panel regression model with $N$ cross-sections and $T$ observations and will producing $m+1$ regimes when there are $m$ potential thresholds allowed in the regression. The regressors are also divided into two groups, which are the threshold regressors and non-threshold regressors. The Panel Threshold regression specification with $r$ non-threshold regressors and $p$ threshold regressors in the regime $j$ is given by [38]:

$$
y_{i t}=\mu_{i}+\boldsymbol{\beta}^{\prime} \mathbf{X}_{\mathbf{i t}}+\sum_{j=1}^{m+1} I_{j}\left(q_{i t}\right) \boldsymbol{\varphi}_{\mathbf{j}}^{\prime} \mathbf{Z}_{\mathbf{i t}}+\varepsilon_{i t}
$$

where $\mu_{i}=$ constant, $\boldsymbol{\beta}=(r \times 1)$ coefficient vector of the non-threshold regressors; $\mathbf{X}_{\mathbf{i t}}=$ $(r \times 1)$ vector of the non-threshold regressors; $\boldsymbol{\varphi}_{\mathbf{j}}=(p \times 1)$ coefficient vector of the threshold regressors at regime $\boldsymbol{j}$ and $\mathbf{Z}_{\mathbf{i t}}=(p \times 1)$ vector of the threshold regressors.

Suppose that there is an observable threshold variable $q_{t}$ and strictly increasing threshold values. The threshold value with $\boldsymbol{j}$-th regime is defined as follows:

$$
q_{i t}(j)=\left\{\begin{array}{l}
q_{i t}(j)<\gamma_{1}, \mathrm{j}=1 \\
\gamma_{j-1} \leq q_{i t}(j)<\gamma_{j}, j=2,3, \ldots, m \\
q_{i t}(j) \geq \gamma_{m}, \mathrm{j}=m+1
\end{array}\right.
$$

In this study, the maximum number of thresholds that considered is 2 . We will assign the threshold variable one-by-one with different number of thresholds and the thresholds that produce good results will be chosen. The Panel Threshold Regression specification with single threshold and double thresholds are defined as follows in structural and alternative way [37], [38]: 


\section{Single Threshold (Two regimes model):}

(a) Structural:

$$
\Delta y_{i t}=\mu_{i}+\boldsymbol{\beta}^{\prime} \mathbf{X}_{\mathbf{i t}}+I\left(q_{i t}<\gamma\right) \boldsymbol{\varphi}^{\prime}{ }_{\mathbf{1}} \mathbf{Z}_{\mathbf{i t}}+I\left(q_{i t} \geq \gamma\right) \boldsymbol{\varphi}^{\prime}{ }_{\mathbf{2}} \mathbf{Z}_{\mathbf{i t}}+\varepsilon_{i t}
$$

(b) Alternative:

$$
\begin{aligned}
\Delta y_{i t} & =\mu_{i}+\boldsymbol{\beta}^{\prime} \mathbf{X}_{\mathbf{i t}}+\boldsymbol{\varphi}^{\prime}{ }_{1} \mathbf{Z}_{\mathbf{i t}}+\varepsilon_{i t}, q_{i t}<\gamma \\
\Delta y_{i t} & =\mu_{i}+\boldsymbol{\beta}^{\prime} \mathbf{X}_{\mathbf{i t}}+\boldsymbol{\varphi}^{\prime}{ }_{\mathbf{2}} \mathbf{Z}_{\mathbf{i t}}+\varepsilon_{i t}, q_{i t} \geq \gamma
\end{aligned}
$$

2. Double Thresholds (Three regimes model):

(a) Structural:

$$
\begin{aligned}
\Delta y_{i t}= & \mu_{i}+\boldsymbol{\beta}^{\prime} \mathbf{X}_{\mathbf{i t}}+I\left(q_{i t}<\gamma_{1}\right) \boldsymbol{\varphi}^{\prime}{ }_{\mathbf{1}} \mathbf{Z}_{\mathbf{i t}}+I\left(\gamma_{1} \leq q_{i t}<\gamma_{2}\right) \boldsymbol{\varphi}^{\prime}{ }_{2} \mathbf{Z}_{\mathbf{i t}} \\
& +I\left(q_{i t} \geq \gamma_{2}\right) \boldsymbol{\varphi}^{\prime}{ }_{\mathbf{3}} \mathbf{Z}_{\mathbf{i t}}+\varepsilon_{i t}
\end{aligned}
$$

(b) Alternative:

$$
\begin{aligned}
& \Delta y_{i t}=\mu_{i}+\boldsymbol{\beta}^{\prime} \mathbf{X}_{\mathbf{i t}}+\boldsymbol{\varphi}^{\prime}{ }_{1} \mathbf{Z}_{\mathbf{i t}}+\varepsilon_{i t}, q_{i t}<\gamma_{1} \\
& \Delta y_{i t}=\mu_{i}+\boldsymbol{\beta}^{\prime} \mathbf{X}_{\mathbf{i t}}+\boldsymbol{\varphi}^{\prime}{ }_{2} \mathbf{Z}_{\mathbf{i t}}+\varepsilon_{i t}, \gamma_{1} \leq q_{i t}<\gamma_{2} \\
& \Delta y_{i t}=\mu_{i}+\boldsymbol{\beta}^{\prime} \mathbf{X}_{\mathbf{i t}}+\boldsymbol{\varphi}^{\prime}{ }_{\mathbf{3}} \mathbf{Z}_{\mathbf{i t}}+\varepsilon_{i t}, q_{i t} \geq \gamma_{2}
\end{aligned}
$$

where $I()=$. the indicator function.

In this study, we define $\Delta y_{i t}$ as the sectoral CPI inflation, where $y_{i t}$ is the sectoral CPI indices that defined in Table $1, \boldsymbol{\beta}^{\prime}=\left[\beta_{1}, \beta_{2}, \beta_{3}\right]$ is the vector of coefficients of non-threshold regressors, $\varphi_{\mathbf{j}}^{\prime}=\left[\varphi_{j 1}, \varphi_{j 2}, \varphi_{j 3}\right]$ is the vector of coefficients of threshold regressors at regime $\boldsymbol{j}$ and $\mathbf{X}^{\prime}{ }_{i t}=\left[\Delta L R E E R_{i t}, \Delta L O I L_{i t}, \Delta L I N T_{i t}\right]$ is the vector of non-threshold variables. We will define two sets of threshold variables and threshold regressors and the set of variables that produce better results will be chosen. If $\mathbf{Z}^{\prime}{ }_{i t}=\left[\Delta L C P I_{i t}, \Delta L P P I_{i t}, \Delta L C P_{i t}\right]$, then $q_{i t}=$ $\left(\triangle L C P I u_{i t}, \triangle L P P I u_{i t}, \Delta L C P u_{i t}\right)$ or vice versa, where $\mathbf{Z}_{\text {it }}$ is the vector of threshold regressors and $q_{i t}$ is the list of threshold variables (each variable will be used).

\section{Results and Discussions}

\subsection{Time Series Analysis}

\subsubsection{Unit-root tests}

The results of Augmented Dickey-Fuller (ADF) and Philips Perron (PP) unit-root tests are shown in Table 3. From the results, the researchers observed that both unit-root tests showed similar results. Only a few variables showed significant results at $10 \%, 5 \%$, and $1 \%$ levels, indicating that the null hypothesis of unit-root was rejected so that they were stationary at level. Therefore, first differencing was required for the series since most of the series were not stationary. After taking the first-difference transformation to all the variables, all the variables became significant at most $10 \%$ level, indicating that they were now stationary. 
Table 3: Results of Unit-root Tests for Sectoral CPI Indices and Independent Variables

\begin{tabular}{|l|l|l|l|l|}
\hline \multirow{2}{*}{ Variables } & \multicolumn{2}{|l|}{ Augmented Dickey-Filler (ADF) } & \multicolumn{2}{c|}{ Philips Perron (PP) } \\
\cline { 2 - 5 } & Level & First-difference & Level & First-difference \\
\hline LCPIBEV & -2.7265 & $-3.8605^{* *}$ & $-16.3444^{* * *}$ & $-3.8605^{*}$ \\
LCPICLOTH & -1.6412 & $-3.7624^{* *}$ & $-3.2919^{*}$ & $-3.7624^{* *}$ \\
LCPIFOOD & $-4.4649^{* * *}$ & $-3.7640^{* *}$ & -2.9811 & $-4.7092^{* * *}$ \\
LCPIFURN & -1.8646 & $-4.6956^{* * *}$ & -2.7297 & $-4.6956^{* * *}$ \\
LCPIMED & -2.7880 & $-4.8150^{* * *}$ & $-3.3517^{*}$ & $-4.8150^{* * *}$ \\
LCPIMISC & -2.9052 & $-5.7142^{* * *}$ & $-4.1399^{* *}$ & $-5.7142^{* * *}$ \\
LCPIPOW & $-3.7064^{* *}$ & $-3.6573^{* *}$ & $-3.9723^{* *}$ & $-3.2491^{*}$ \\
LCPIREC & -2.8793 & $-5.0355^{* * *}$ & -1.6351 & $-4.8535^{* * *}$ \\
LCPITRAN & -0.0211 & $-4.7081^{* * *}$ & -0.0211 & $-4.7081^{* * *}$ \\
\hline LCPI & -2.0817 & -5.0577 & -3.1816 & $-5.0577^{* * *}$ \\
LPPI & -2.5455 & $-5.9884^{* * *}$ & -2.5455 & $-5.9884^{* * *}$ \\
LCP & -2.0111 & $-4.7850^{* * *}$ & -2.4221 & $-4.7850^{* * *}$ \\
LOIL & -2.0156 & $-5.6032^{* * *}$ & -2.0156 & $-5.6032^{* * *}$ \\
LINT & $-3.2592^{*}$ & $-6.0775^{* * *}$ & $-3.2592^{*}$ & $-6.0775^{* * *}$ \\
LREER & -2.4316 & $-4.4144^{* * *}$ & -2.5839 & $-4.4144^{* * *}$ \\
LCPIu & $-5.2807^{* * *}$ & $-6.6383^{* * *}$ & $-5.2807^{* * *}$ & $-8.0893^{* * *}$ \\
LPPIu & -2.7910 & $-6.0999^{* * *}$ & -2.7910 & $-6.0999^{* * *}$ \\
LCPu & $-5.9026^{* * *}$ & $-6.3316^{* * *}$ & $-5.9026^{* * *}$ & $-8.2210^{* * *}$ \\
\hline
\end{tabular}

Note: $*, * *$, and $* * *$ indicate rejection of the null hypothesis of a unit root at the $10 \%, 5 \%$ and $1 \%$ level of significance respectively.

\subsubsection{Threshold GARCH (TGARCH) Analysis}

The results of TGARCH are summarised in Table 4. The mean equations captured the linkages between the inflation of commodities, CPI, and PPI. CPI inflation was impacted by PPI and commodities inflation and its lag term; PPI inflation was impacted by CPI inflation; and commodity price inflation was determined by oil price inflation. The variance equations explained the volatility/uncertainty of these three variables. The CPI and PPI inflation uncertainties were not well-explained by any volatility; the commodity price inflation uncertainty was well-explained by its short-term volatility; and the good news effect as the threshold indicator was in negative value. The three inflation uncertainties series were generated and used in the threshold regression.

\subsubsection{Threshold Regression Analysis}

The results of threshold regression estimations are shown in Table 5 and Table 6 . The researchers observed the existence of threshold effect in all estimated models with one or two thresholds. The direct effect of an explanatory variable was observed based on the coefficients estimated, while the indirect effect was captured when a variable was treated as a threshold 
Table 4: Mean and Variance Equations of TGARCH Models

\begin{tabular}{|l|l|l|l|l|l|}
\hline \multicolumn{7}{|c|}{$\Delta L C P I_{t}$} & \multicolumn{2}{c|}{$\Delta L P P I_{t}$} & \multicolumn{2}{c|}{$\Delta L C P_{t}$} \\
\hline \multicolumn{6}{|c|}{ Mean Equations } \\
\hline Predictors & Coefficients & Predictors & Coefficients & Predictors & Coefficients \\
\hline $\mathrm{C}$ & $-0.7718^{* * *}$ & $\mathrm{C}$ & $-4.4203^{* * *}$ & $\mathrm{C}$ & 0.0065 \\
$\Delta L C P I_{t-1}$ & $0.0600^{* * *}$ & $\Delta L P P I_{t-1}$ & -0.0698 & $\Delta L C P I_{t-1}$ & -0.0311 \\
$\Delta L P P I_{t}$ & $-0.0871^{* * *}$ & $\Delta L C P I_{t}$ & $-5.3698^{* * *}$ & $\Delta L O I L_{t}$ & $0.2341^{* * *}$ \\
$\Delta L C P_{t}$ & $0.0223^{* * *}$ & $\Delta L C P_{t}$ & 0.0145 & - \\
\hline \multicolumn{7}{|c|}{ Variance Equations } & Coefficients \\
\hline Predictors & Coefficients & Predictors & Coefficients & Predictors & $0.0010^{*}$ \\
\hline $\mathrm{C}$ & 0.0001 & $\mathrm{C}$ & 0.0001 & -0.0018 \\
$\sigma_{t-1}^{2}$ & -0.0581 & $\sigma_{t-1}^{2}$ & 0.1144 & $\sigma_{t-1}^{2}$ & $-0.3101^{* *}$ \\
$I_{t-1} \varepsilon_{t-1}^{2}$ & -0.1234 & $I_{t-1} \varepsilon_{t-1}^{2}$ & -1.2230 & $I_{t-1} \varepsilon_{t-1}^{2}$ & $0.6571^{* *}$ \\
$\varepsilon_{t-1}^{2}$ & 0.5806 & $\varepsilon_{t-1}^{2}$ & 0.5868 & $\varepsilon_{t-1}^{2}$ & 0.8202 \\
\hline \multicolumn{7}{|c|}{ Diagnostics (ARCH-LM F-test) $($ Lag 2$)$} & \\
\hline
\end{tabular}

Note: $*,{ }^{* *}$, and ${ }^{* * *}$ indicate the significance of coefficients or ARCH-LM F-tests at the level of $10 \%, 5 \%$ and $1 \%$ respectively. The variables in the first row represent the dependent variable of the mean equation.

variable; its effect on the dependent variable was not directly observable, but through its impact on the regime-dependent variables. In the discussions, positive relation will be denoted as a negative effect because higher inflation was a bad outcome, while negative relation was a positive impact.

The analysis was carried out by treating different variables as threshold variables, but only one threshold variable was selected which show the largest impact. The search limit was at most two threshold values, using the sequential algorithms. The results summarised were based on the most impactful threshold effects. The threshold value detected had separated the regression into different regimes. There were two regimes (below and above the threshold value) in the case when one threshold value was detected. There were three threshold regimes (below the first threshold value, between the first and second threshold values, and above the second threshold value) for two thresholds model. The detection of threshold values implied that the CPI inflation equation was nonlinear.

The global CP inflation (acted as threshold variable) had an indirect effect on the CPI inflation of alcoholic beverages and tobacco; and transport and communication sectors (Table 5). When the commodity price inflation was low (first regime), higher CPI inflation uncertainty led to lower CPI inflation in these two sectors. Lower commodity price led to lower production costs and the effect was more felt in the beverages sector. At the same time, stiff competition would have occurred among the competitors. Consumers were uncertain with the products and services because there were many communication products and transportation services in the market. So, the consumer price had dropped to overcome the stiff competition situation. When the commodity price inflation was high, the increase in CP inflation uncertainty led to higher inflation in the transport and communication sector in both second and third regimes, but the 
effects were less sensitive. Higher commodity price led to higher production cost which passed through to higher consumer price in these two sectors.

On the other hand, when PPI inflation was selected as the threshold variables, its threshold effect/indirect effect on the clothing and footwear; food and non-alcoholic beverages; and furniture, furnishing, and housing equipment sectors were observed (see the last three columns in Table 5). Again, the threshold variable had led to varying relationship between CPI inflation and explanatory variables across different regimes. For instance, all CPI, PPI, and CP inflation uncertainties had no significant effect on the CPI inflation in furniture sector when the PPI inflation was low (first regime). However, PPI and CP inflation uncertainties had caused higher CPI inflation in this sector in the second regime. The results also revealed that the CPI inflation of food and non-alcoholic beverages sector was very sensitive to CPI uncertainty in the third regime, while the CPI inflation of clothing and footwear sector was well-explained by the PPI uncertainty; higher PPI or CPI uncertainty had contributed to higher CPI inflation in these sectors.

It was observed that the threshold regressors $\left(\triangle L C P I u_{t}, \triangle L P P I u_{t}, \Delta L C P u_{t}\right)$ exhibited larger positive coefficient values than the negative values across regimes and sectors, indicating that these types of uncertainty impose larger negative effect (leads to higher CPI inflation) relative to its positive effect (leads to lower CPI inflation) across five sectors in Table 5. The same condition also holds in other four sectors as shown in Table 6 when CPI inflation uncertainty was selected as the threshold variable. CPI inflation uncertainty had triggered different reactions of CPI inflation to the threshold regressors (i.e., CPI, PPI, and CP inflations) across sectors. The negative effect (leads to higher CPI inflation, positive coefficient) was larger than the positive effect (leads to lower CPI inflation, negative coefficient). Table 6 also showed that the medical service sector was highly induced by CPI inflation in regime 2 .

Apart from the threshold regressors, non-threshold regressors also had a high impact on CPI inflation. From Table 5 and Table 6, it is observed that an increase in oil price inflation only causes higher CPI inflation in the transport sector, but it reduces the CPI inflation in other sectors. Although higher oil price had led to higher production cost, its impact did not transmit into higher consumer final goods. This would have been due to the effective monetary policy or control on pricing by the government on necessity goods. On the other hand, exchange rate changes were also an important factor. An increase (appreciation) in the exchange rate changes tended to increase the CPI inflation in majority sectors. Overall, the results revealed that PPI and commodities inflation and the three inflation uncertainties can influence CPI inflation either directly or indirectly. Their effects varied across sectors and regimes. The external factors (exchange rate and oil price inflation) were influential on CPI inflation in a majority of sectors as compared to the interest rate (domestic factor), which was less influential.

\subsubsection{Diagnostic Tests}

The diagnostic tests results are shown in Table 4, Table 5, and Table 6. For TGARCH analysis, the ARCH-LM test with lag 2 was conducted to test the presence of heteroscedasticity in the residuals (Table 4). Based on the results, the F-statistics were all insignificant, indicating that the null hypothesis of residuals were homoscedastic and was not rejected. Therefore, the evidence of no heteroscedastic variance in residuals have been shown, and thus, all models of TGARCH were well fitted. 
Table 5: Threshold Estimations of $\triangle L C P I B E V_{t}, \triangle L C P I T R A N_{t}, \quad \triangle L C P I C L O T H_{t}$, $\triangle L C P I F O O D_{t}$ and $\triangle L C P I F U R N_{t}$

\begin{tabular}{|c|c|c|c|c|c|}
\hline $\begin{array}{l}\text { Dependent } \\
\text { Variable }\end{array}$ & $\triangle L C P I B E V_{t}$ & $\triangle L C P I T R A N_{t}$ & $\Delta L C P I C L O T H_{t}$ & $\triangle L C P I F O O D_{t}$ & $\triangle L C P I F U R N_{t}$ \\
\hline \multicolumn{2}{|c|}{ Threshold Variable Considered } & \multicolumn{4}{|c|}{$\Delta L C P I_{t}, \Delta L P P I_{t}, \Delta L C P_{t}$} \\
\hline $\begin{array}{l}\text { Threshold } \\
\text { Variable Chosen }\end{array}$ & \multicolumn{2}{|c|}{$\Delta L C P_{t}$} & \multicolumn{3}{|c|}{$\triangle L P P I_{t}$} \\
\hline Threshold values & 0.0255 & $\begin{array}{l}0.0016 \\
0.0594\end{array}$ & $\begin{array}{l}-0.0307 \\
-0.0244\end{array}$ & $\begin{array}{l}-0.0365 \\
-0.0052\end{array}$ & -0.0246 \\
\hline \multicolumn{6}{|c|}{ Threshold Regressors } \\
\hline \multicolumn{6}{|l|}{ First Regime } \\
\hline $\begin{array}{l}\varphi_{0} \\
\Delta L C P I u_{t} \\
\Delta L P P I u_{t} \\
\Delta L C P u_{t}\end{array}$ & $\begin{array}{l}0.0699^{* * *} \\
-0.1478^{* *} \\
-0.0857^{*} \\
0.0046\end{array}$ & $\begin{array}{l}0.0345^{* * *} \\
-0.0739^{* *} \\
-0.0386 \\
-0.0014\end{array}$ & $\begin{array}{l}-0.0063 \\
0.0058^{* *} \\
-0.0516^{* *} \\
0.0072^{* * *}\end{array}$ & $\begin{array}{l}0.0559^{* * *} \\
0.0079^{*} \\
-0.0384 \\
0.0198\end{array}$ & $\begin{array}{l}0.0214^{* * *} \\
0.0027 \\
-0.0152 \\
0.0016\end{array}$ \\
\hline \multicolumn{6}{|l|}{ Second Regime } \\
\hline $\begin{array}{l}\varphi_{0} \\
\Delta L C P I u_{t} \\
\Delta L P P I u_{t} \\
\Delta L C P u_{t}\end{array}$ & $\begin{array}{c}0.1160^{* * *} \\
-0.0194^{*} \\
0.2950^{* *} \\
-0.0117^{*} \\
\end{array}$ & $\begin{array}{l}-0.0020 \\
0.4364^{* * *} \\
-0.1060 \\
0.0396^{* *} \\
\end{array}$ & $\begin{array}{l}0.0129^{* * *} \\
-0.0544 \\
-0.0144 \\
-0.0256^{* * *} \\
\end{array}$ & $\begin{array}{l}0.0289 * * * \\
0.0028 \\
0.0020 \\
-0.0042 \\
\end{array}$ & $\begin{array}{l}0.0029 \\
0.0307 \\
0.0424^{* * *} \\
0.0037^{* * *}\end{array}$ \\
\hline \multicolumn{6}{|l|}{ Third Regime } \\
\hline $\begin{array}{l}\varphi_{0} \\
\Delta L C P I u_{t} \\
\Delta L P P I u_{t} \\
\Delta L C P u_{t}\end{array}$ & $\begin{array}{l}- \\
- \\
- \\
-\end{array}$ & $\begin{array}{c}0.0043 \\
0.0029 \\
-0.0191 \\
0.0071^{*}\end{array}$ & $\begin{array}{l}-0.0015 \\
-0.0380^{*} \\
0.0708^{* * *} \\
0.0012\end{array}$ & $\begin{array}{l}-0.0260 \\
0.3434^{* *} \\
0.2258^{*} \\
0.0037\end{array}$ & $\begin{array}{l}- \\
- \\
- \\
-\end{array}$ \\
\hline \multicolumn{6}{|c|}{ Non-Threshold Regressors } \\
\hline $\begin{array}{l}\Delta L O I L_{t} \\
\Delta L I N T_{t} \\
\Delta L R E E R_{t}\end{array}$ & $\begin{array}{l}-0.0972^{* *} \\
-0.0704 \\
-0.2395^{*}\end{array}$ & $\begin{array}{l}0.0621^{* *} \\
0.0480^{* *} \\
0.0599\end{array}$ & $\begin{array}{l}-0.0290^{* * *} \\
0.0374^{* * *} \\
0.0778^{*}\end{array}$ & $\begin{array}{l}0.0048 \\
0.0064 \\
-0.2568 * * *\end{array}$ & $\begin{array}{l}-0.0305^{* * *} \\
0.0160 \\
-0.0616\end{array}$ \\
\hline \multicolumn{6}{|c|}{ Diagnostic Tests } \\
\hline $\begin{array}{l}\text { BG-LM F test } \\
\text { ARCH-LM F test }\end{array}$ & $\begin{array}{l}0.9531(1) \\
0.6420(1)\end{array}$ & $\begin{array}{l}0.0081(1) \\
0.6365(1)\end{array}$ & $\begin{array}{l}0.1668(1) \\
0.0059(1)\end{array}$ & $\begin{array}{l}0.6569(1) \\
0.3460(1)\end{array}$ & $\begin{array}{l}0.1382(1) \\
1.3335(1)\end{array}$ \\
\hline
\end{tabular}

Note: $*, * *$, and $* * *$ indicate the significance of coefficients or diagnostics F-statistics at the level of $10 \%$, $5 \%$ and $1 \%$ respectively. The parentheses values in last two rows represent the number of lags used in the diagnostic tests. 
Table 6: Threshold Estimations of $\triangle L C P I M E D_{t}, \triangle L C P I M I S C_{t}, \triangle L C P I P O W_{t}$ and $\triangle L C P I R E C_{t}$

\begin{tabular}{|c|c|c|c|c|}
\hline $\begin{array}{l}\text { Dependent } \\
\text { Variable }\end{array}$ & $\triangle L C P I M E D_{t}$ & $\Delta L C P I M I S C_{t}$ & $\triangle L C P I P O W_{t}$ & $\triangle L C P I R E C_{t}$ \\
\hline \multicolumn{2}{|l|}{$\begin{array}{l}\text { Threshold Variable } \\
\text { Considered }\end{array}$} & \multicolumn{3}{|c|}{$\Delta L C P I u_{t}, \Delta L P P I u_{t}, \Delta L C P u_{t}$} \\
\hline \multirow{2}{*}{ Variable Chosen } & \multicolumn{4}{|c|}{$\Delta L C P I u_{t}$} \\
\hline & 0.1577 & 0.0583 & & 0.1593 \\
\hline \multicolumn{5}{|c|}{ Threshold Regressors } \\
\hline \multicolumn{5}{|l|}{ First Regime } \\
\hline $\begin{array}{l}\varphi_{0} \\
\Delta L C P I_{t} \\
\Delta L P P I_{t} \\
\Delta L C P_{t}\end{array}$ & $\begin{array}{l}2.0202 \\
2.4134 \\
0.6317^{*} \\
-0.0305\end{array}$ & $\begin{array}{l}5.2737^{* *} \\
6.3851^{* *} \\
0.8325^{* *} \\
-0.0358\end{array}$ & $\begin{array}{l}5.5653^{* * *} \\
6.7323^{* * *} \\
1.0599^{* * *} \\
-0.0789\end{array}$ & $\begin{array}{l}3.0212^{*} \\
3.6603^{*} \\
0.3352 \\
-0.0879\end{array}$ \\
\hline \multicolumn{5}{|l|}{ Second Regime } \\
\hline $\begin{array}{l}\varphi_{0} \\
\Delta L C P I_{t} \\
\Delta L P P I_{t} \\
\Delta L C P_{t}\end{array}$ & $\begin{array}{l}-83.2498^{* * *} \\
101.3115^{* * *} \\
-11.5776^{* * *} \\
3.1010^{* * *}\end{array}$ & $\begin{array}{l}-4.6668 \\
-5.6950 \\
-1.0859 \\
0.1942^{*}\end{array}$ & $\begin{array}{l}-2.3768 \\
-2.8749 \\
-1.1945 \\
-0.1220\end{array}$ & $\begin{array}{l}-7.4151^{*} \\
9.0366^{*} \\
-1.2024 \\
0.4170^{* * *}\end{array}$ \\
\hline \multicolumn{5}{|c|}{ Non-Threshold Regressors } \\
\hline $\begin{array}{l}\Delta L O I L_{t} \\
\Delta L I N T_{t} \\
\Delta L R E E R_{t}\end{array}$ & $\begin{array}{l}-0.0208 \\
-0.0047 \\
0.1447^{* *}\end{array}$ & $\begin{array}{l}-0.0354^{*} \\
-0.0015 \\
0.0572\end{array}$ & $\begin{array}{l}-0.0438^{* *} \\
-0.0130 \\
0.2633^{* * *}\end{array}$ & $\begin{array}{l}-0.0087 \\
-0.0034 \\
0.0035^{*}\end{array}$ \\
\hline \multicolumn{5}{|c|}{ Diagnostic Tests } \\
\hline BG-LM F test & $2.4952(2)$ & $2.0742(1)$ & $2.0642(2)$ & $1.8224(2)$ \\
\hline
\end{tabular}

Note: ${ }^{*}, * *$, and ${ }^{* * *}$ indicate the significance of coefficients or diagnostics F-statistics at the level of $10 \%, 5 \%$ and $1 \%$ respectively. The parentheses values in last two rows represent the number of lags used in the diagnostic tests. 
For threshold regression analysis, the Breusch-Godfrey (BG) LM and ARCH-LM tests were conducted to test the presence of serial correlation and heteroscedasticity in the residuals. The test was initially conducted by using only one lag. If the result was significant, the test will be re-conducted by increasing the number of lags. Based on the results in Table 5 and Table 6, all the F-statistics were insignificant at lag 2 and lag 2. This indicated that the null hypothesis of no serial correlation and no heteroscedasticity was not rejected.

\subsection{Panel Data Analysis}

We combined the nine sectors and stacked the data into the panel data format for further analysis. Prior to the analysis, the panel unit-root tests of Levin, Lin, and Chu (LLC), Breitung t-test and Im, Pesaran, and Shin (IPS) were performed. The results were as summarised in Table 7. The results of panel unit-root tests were reported and the results are shown in Table 7. All variables were stationary at first difference. Therefore, the differenced data were used in the regression analysis.

Table 8 summarises the results of static threshold regression of Hansen (1999). The threshold F-test was used to test the threshold effect. The F-statistics were significant for all models, indicating that the null hypothesis of no threshold effect was rejected. The threshold effect existed in all estimated models. Two thresholds were detected in the model, whereby the CP inflation was the threshold variable, while the other two models had only one threshold.

Table 8 showed the results of estimation by using CPI, PPI, and CP inflations as the threshold variable. The result from panel data analysis was consistent to that in the time series data with varying effects under different regimes. CPI inflation was more sensitive in response to three inflation uncertainties when CP inflation was the threshold variable. When CP inflation was lower at Regime 1 and Regime 2, the increase of PPI and CP inflation uncertainties led to the decline in CPI inflation. However, they led to higher CPI inflation in the third regime. The results implied that when $\mathrm{CP}$ inflation was relatively low, PPI and CP inflation uncertainties stimulated higher production or through higher productivity and the CPI price declines. However, when CP inflation was higher (third regime), PPI and CP uncertainties induced lower production as production cost was expected to increase. This led to the increase of CPI inflation.

The non-threshold regressors also showed very similar result to the one of time series. The exchange rate and oil price changes were more influential in relative to the interest rate changes. Higher oil price change was associated with lower CPI inflation, while appreciation of exchange rate changes led to higher CPI inflation. This was because the exported goods (domestic goods) were more expensive in relative to the imported goods. The overall F test was used to test the overall significance of the predictors to the response variable. Table 8 shows that the F-statistics are significant at $1 \%$ level, indicating that the null hypothesis of no predictor effect is rejected. It can be conclude that the predictors were important in predicting the sectoral inflation.

\section{Conclusions}

In this paper, empirical analyses were conducted to examine the effects of domestic and global price uncertainties to the sectoral inflation in Malaysia. The main objective of this study was to examine the effects of domestic and global inflation uncertainties on Malaysian sectoral CPI 
Table 7: Results of Panel Unit-root Tests for All Variables

\begin{tabular}{|l|l|l|l|l|l|l|}
\hline \multirow{2}{*}{ Variables } & \multicolumn{2}{|l|}{ Levin, Lin and Chu (LLC) } & \multicolumn{2}{l|}{ Im, Pesaran and Shin (IPS) } & \multicolumn{2}{l|}{ Breitung t-stat } \\
\cline { 2 - 7 } & Level & $\begin{array}{l}\text { First- } \\
\text { difference }\end{array}$ & Level & $\begin{array}{l}\text { First- } \\
\text { difference }\end{array}$ & Level & $\begin{array}{l}\text { First- } \\
\text { difference }\end{array}$ \\
\hline LCPIs & -0.3483 & $-4.6730^{* * *}$ & $-1.4588^{*}$ & $-7.8251^{* * *}$ & -1.2595 & $-2.4638^{* * *}$ \\
LCPI & 3.8864 & $-7.2766^{* * *}$ & 0.8703 & $-11.0484^{* * *}$ & 1.0204 & $-2.1999^{* *}$ \\
LPPI & 1.4406 & $-14.9813^{* * *}$ & $-1.3678^{*}$ & $-13.9594^{* * *}$ & -0.0741 & $-14.1805^{* * *}$ \\
LCP & $-2.7835^{* * *}$ & $-13.6691^{* * *}$ & -0.9151 & $-9.5571^{* * *}$ & 2.3927 & $-6.2935^{* * *}$ \\
LOIL & -0.2849 & $-9.8650^{* * *}$ & 0.5758 & $-12.5502^{* * *}$ & 2.0837 & $-10.8444^{* * *}$ \\
LINT & $-7.2655^{* * *}$ & $-17.9817^{* * *}$ & $-3.9854^{* * *}$ & $-14.2856^{* * *}$ & $-7.6978^{* * *}$ & $-17.3679^{* * *}$ \\
LREER & -0.4918 & $-11.6120^{* * *}$ & -0.9134 & $-8.2013^{* * *}$ & $-4.4179^{* * *}$ & $-11.3062^{* * *}$ \\
LCPIu & $-11.0238^{* * *}$ & $-6.0082^{* * *}$ & $-11.3414^{* * *}$ & $-15.7343^{* * *}$ & $-11.4763^{* * *}$ & $-17.3028^{* * *}$ \\
LPPIu & $-1.9047^{* *}$ & $-17.7252^{* * *}$ & $-2.2573^{* *}$ & $-14.2940^{* * *}$ & $-3.9174^{* * *}$ & $-17.3098^{* * *}$ \\
LCPu & $-16.3737^{* * *}$ & $-15.3647^{* * *}$ & $-13.6108^{* * *}$ & $-14.6533^{* * *}$ & $-13.2154^{* * *}$ & $-18.9104^{* * *}$ \\
\hline
\end{tabular}

Note: ${ }^{*},{ }^{* *}$, and ${ }^{* * *}$ indicate rejection of the null hypothesis of a unit root at the $10 \%, 5 \%$ and $1 \%$ level of significance respectively

inflation. The TGARCH model was used to generate the inflation uncertainty series and the effects were analysed by using the Threshold regression and panel Threshold regression models. However, the researchers found that inflation uncertainty factors had indirect or direct effects to the sectoral inflation. The main focus was on the inflation and inflation uncertainty factors to see how much it affected the sectoral CPI inflation in Malaysia. From the nine estimated threshold regression models, the main determinant factors that affected the sectoral inflation were the inflation and inflation uncertainty variables, except for the CPI clothing sector that was mainly affected by the exchange rate. From the inflation uncertainty factors, only domestic inflation uncertainty had main effects to the selected sectoral inflation. For inflation factors, only domestic CPI inflation had mainly affected the selected sectoral inflation. From the three estimated panel data models, the domestic inflation uncertainty and exchange rate factors had mainly affected the sectoral inflation. A study by Daniela et al. (2014) supported the existence of the relation between inflations and inflation uncertainties. The results also showed that the domestic inflation and uncertainty factors were more dominant than the global inflation factors (CP inflation and uncertainty factors). The CP inflation and uncertainty had more dominant effects to the commodity-based sectors, especially the furniture, transport, and miscellaneous goods sectors inflation.

For other fundamental factors, the exchange rate appreciation led to higher CPI inflation in most sectors, as validated by Justine et al. (2017), and the exchange rate pass-through theory that was provided by Chabot and Khan (2015). The interest rate had affected the sectoral inflation due to the cost of borrowing or savings, but the effects were less sensitive to the sectoral inflation. The oil price inflation was more dominant to the oil-intensive sectors. The effect of oil price had caused the inflation of oil intensive sectors to increase, while a decrease for non-oil intensive sectors. A study by Sek (2017) showed similar results. In the panel data analysis, the results were also similar to the threshold regression analysis.

Overall, the inflation was determined by prices or price uncertainties which could lead to price fluctuations in certain sectors. The effect of price increases was larger than the effect of price decreases. The price fluctuations were obvious for the sectors that were dependent 
Table 8: Panel Threshold Estimations of Sectoral CPI Inflation

\begin{tabular}{|c|c|c|c|}
\hline \multicolumn{4}{|c|}{$\begin{array}{l}\text { Dependent Variable: } \triangle L C P I s_{i t} \\
\text { Threshold Variable Considered: } \triangle L C P I_{i t}, \Delta L P P I_{i t}, \Delta L C P_{i t}\end{array}$} \\
\hline Threshold Variable Chosen & $\triangle L C P I_{i t}$ & $\triangle L P P I_{i t}$ & $\Delta L C P_{i t}$ \\
\hline Threshold values & 0.0163 & -0.0029 & $-0.0931,0.0565$ \\
\hline \multicolumn{4}{|c|}{ Threshold Regressors } \\
\hline \multicolumn{4}{|l|}{ First Regime } \\
\hline$\Delta L C P I u_{i t}$ & $0.0342^{* * *}$ & $-0.0426^{* * *}$ & -0.0008 \\
\hline$\Delta L P P I u_{i t}$ & $0.0210^{*}$ & -0.0105 & $-0.4386^{* *}$ \\
\hline$\Delta L C P u_{i t}$ & $0.0017^{* *}$ & $0.0023^{* * *}$ & -0.0007 \\
\hline \multicolumn{4}{|l|}{ Second Regime } \\
\hline$\Delta L C P I u_{i t}$ & 0.0020 & 0.0020 & $-0.0360^{* * *}$ \\
\hline$\Delta L P P I u_{i t}$ & 0.0082 & 0.0020 & $-0.0175^{* *}$ \\
\hline$\Delta L C P u_{i t}$ & $0.0822^{* *}$ & 0.0001 & $-0.0088^{* * *}$ \\
\hline \multicolumn{4}{|c|}{ Third Regime } \\
\hline$\Delta L C P I u_{i t}$ & - & - & $-0.2312^{* * *}$ \\
\hline$\Delta L P P I u_{i t}$ & - & - & $0.2698^{* * *}$ \\
\hline$\Delta L C P u_{i t}$ & - & - & $0.0025^{* * *}$ \\
\hline \multicolumn{4}{|c|}{ Non-Threshold Regressors } \\
\hline$\Delta L O I L_{i t}$ & $-0.0209^{* * *}$ & $-0.0236^{* * *}$ & $-0.0176^{* *}$ \\
\hline$\Delta L I N T_{i t}$ & $0.0106^{* *}$ & 0.0056 & -0.0015 \\
\hline$\Delta L R E E R_{i t}$ & $0.6741^{* *}$ & $0.0496^{*}$ & $0.1439^{* * *}$ \\
\hline$\mu_{i}$ & $0.0266^{* * *}$ & $0.0270^{* * *}$ & $0.0300^{* * *}$ \\
\hline \multicolumn{4}{|c|}{ Preliminary and Diagnostic Tests } \\
\hline Threshold F test & $15.78^{* * *}(1)$ & $13.53^{* *}(1)$ & $20.05^{*}(2)$ \\
\hline Overall F test & $17.90^{* * *}$ & $17.68^{* * *}$ & $18.93^{* * *}$ \\
\hline
\end{tabular}

Note: $* * *$, and $* * *$ indicate the significance of coefficients or F-statistics at the level of $10 \%$, $5 \%$ and $1 \%$ respectively. The parentheses values in second last rows represent the number of thresholds detected.

on consumer price or commodity price. The increase in the sectoral price will cause higher inflation to the domestic economy. Since domestic CPI prices were affected by price changes and uncertainty, including global commodity price uncertainty, it is crucial for policymakers to take prevention action to maintain price stability. In creating a low inflationary environment, policymakers should target on low inflation or set price stability as its main policy objective. An effective monetary policy is able to influence household expectation and price level. When the price is high, contractionary policy should be put into action by increasing the interest rate, while expansionary policy should be put into action to boost the economic growth during economic recession. The price control action can also be done by the government like imposing ceiling price for necessity goods, such as foods, especially during festival seasons. Subsidies can also be given to producers to reduce production costs, such as oil, medical, and education subsidies so that the price can be controlled. 


\section{Acknowledgements}

This project is part of the research funded by FRGS (203/PMATHS/6711687).

\section{References}

[1] Ramlee, M. H. and Rani, M. S. A. Core inflation: The Malaysian case. Advances in Economics and Business. 2016. 4(11): 674-690.

[2] Cheng, M. Y. and Tan, H. B. Inflation in Malaysia. International Journal of Social Economics. 2002. 29(5): 411-425.

[3] Murdipi, R. and Law, S. H. Dynamic linkages between price indices and inflation in Malaysia. Jurnal Ekonomi Malaysia. 2016. 50(1): 41-52.

[4] Islam, R. , Ghani, A. B. A. , Mahyuddin, E. and Manickam, N. Determinants of factors that affecting inflation in Malaysia. International Journal of Economics and Financial Issues. 2016. 7(2): 355-364.

[5] Central Bank Malaysia Annual Report. 2010. Retrieved from: http://www.bnm.gov.my/ files/publication/ar /en/2010/ar2010_book.pdf

[6] Malaysia Economic Reports. 1994-2017). Retrieved from: http://www.treasury.gov.my/ index.php/en/archives.html

[7] Clark, T. Do producer prices lead consumer prices?. Federal Reserve Bank of Kansas City Economic Review. 1995. Third Quarter: 25-39.

[8] Anggraeni, D. \& Irawan, T. Causality analysis of Producer Price Index (PPI) and Consumer Price Index (CPI) in Indonesia. Jurnal Ekonomi dan Kebijakan Pembangunan. 2018. 7(1): 60-77.

[9] Central Bank Malaysia Annual Report. 2011. Retrieved from: http://www.bnm.gov.my/ files/publication/ar /en/2011/ar2011_book.pdf

[10] Blomberg, S. B. and Harris, E. S. The Commodity-Consumer Prices Connection: Fact or Fable? Economic Policy Review. 1(3): Federal Reserve Bank of New York. 1995.

[11] Chabot, L. S. and Khan, M. Exchange Rate Pass-Through to Consumer Prices: Theory and Recent Evidence. Discussion Papers: 2015-9, Bank of Canada. 2015.

[12] Bailliu, J. and Fujii, E. Exchange Rate Pass-Through and the Inflation Environment in Industrialized Countries: An Empirical Investigation. Staff Working Papers: 2004-21, Bank of Canada. 2004.

[13] Rizvi, S. K. A. and Naqvi, B. Asymmetric behavior of inflation uncertainty and FriedmanBall hypothesis: evidence from Pakistan. The Lahore Journal of Economics. 2010. 15(2): $1-33$.

[14] Tao, R. , Li, Z. Z. , Li, X. L. and Su, C. W. A Reexamination of Friedman-Ball's Hypothesis in Slovakia - Evidence from Wavelet Analysis. Romanian Journal of Economic Forecasting. 2018. 21(4): 41-54.

[15] Golob, J. E. Does inflation uncertainty increase with inflation? Economic Review, Federal Reserve Bank of Kansas City. 1994. 79(3): 27-38. 
[16] Justine, W. Y. M. , Lim, Y. T. , Loke, H. Y. and Tai, J. J. Effect of Macroeconomic Variables Toward Inflation in Malaysia's Economy. Undergraduate Thesis. Universiti Tunku Abdul Rahman, Malaysia. 2017.

[17] Ruzima, M. and Veerachamy, P. A Study on Determinants of Inflation in Rwanda from 1970-2013. International Journal of Management and Development Studies. 2015. 4(4): 390-401.

[18] Hassan, M. S. , Islam, F. and Ijaz, M. Inflation in Pakistan: evidence from ARDL bounds testing approach. International Journal Management Development. 2016. 1(2): 181-195.

[19] Kiganda, E. O. , Adhiambo, S. and Obange, N. Exports as a determinant of inflation in Kenya: disaggregated econometric analysis. European Scientific Journal. 2017. 13(9): 417-432.

[20] Jayawardana, D. and Jayasingle, P. An inquiry into the causes of inflation in Sri Lanka: an eclectic approach. NSBM Journal of Management. 2016. 2(1): 92-105.

[21] Enu, P. and Havi, E. D. K. Macroeconomic determinants of inflation in Ghana: a cointegration approach. International Journal of Financial Research. 2014. 7(2): 233-246.

[22] Sek, S. K. Impact of oil price changes on domestic price inflation at disaggregated levels: Evidence from linear and nonlinear ARDL modeling. Energy. 2017. 130: 204-217.

[23] Sek, S. K. Effect of Oil Price pass-through on domestic price inflation: evidence from nonlinear ARDL models. Panoeconomicus. 2019. 66(1): 69-91.

[24] Sek, S. K. , Teo, X. Q. and Wong, Y. N. A Comparative Study on the Effects of Oil Price Changes on Inflation. In proceedings for the 4 th World Conference on Business, Economics and Management (WCBEM), Turkey. Malaysia: Procedia Economics and Finance. 2015. 630-636.

[25] Chuah, K. P. , Eilyn, C. and Tan, J. S. The Impact of Global Commodity Prices on Inflation in Malaysia. 2013. Working Paper, Bank Negara Malaysia. Retrieved from: https://www.statistics.gov.hk/wsc/STS081-P2-S.pdf.

[26] Rasasi, M. A. , Algahtani, G. and Alqahtani, A. The effects of global commodity prices on domestic prices in Saudi Arabia. International Journal of Economics and Financial Issues. 2017. 7(4): 590-594.

[27] Moradi, M. A. A GARCH model of inflation and inflation uncertainty in Iran. The Economic Research. 2006. 6(1): 121-145.

[28] Daniela, Z. , Ioan, C. M. and Sorina, P. Inflation uncertainty and inflation in the case of Romania, Czech Republic, Hungary, Poland and Turkey. Procedia Economics and Finance. 2014. 15: $1225-1234$.

[29] Engle, R. F. Autoregressive conditional heteroscedasticity with estimates of the variance of United Kingdom Inflation. Econometrica. 1982. 50(4): 987-1008.

[30] Bollerslev, T. Generalized autoregressive conditonal heteroskedasticity. Journal of Econometrics. 1986. 31(3): 307-327.

[31] Zakoian, J. M. Threshold heteroskedastic models. Unpublished paper, Institut National de la Statistique et des Etudes Economiques, Paris. 1991. 
[32] Glosten, L. R., Jagannathan, R. and Runkle, D. E. On the relation between the expected value and the volatility of the nominal excess return on stocks. Journal of Finance. 1993. 48(5): 1779-1801.

[33] Chin, L. C. , Sek, S. K. and Tan, Y. T. A Sectorial Performance Analysis of Kuala Lumpur Stock Exchange (KLSE, Bursa Malaysia). MPRA Papers. 2018. No. 90148. Available at URI: https://mpra.ub.uni-muenchen.de/id/eprint/90148

[34] Wu, J. Threshold GARCH Model: Theory and Application. 2011. Retrieved from: http://publish.uwo.ca/〜jwu87/files/JobMarketPaper_JingWu.pdf.

[35] Akesson, A. Inflation and Inflation Uncertainty in Sweden: a GARCH Modelling Approach. LUP Student Papers. 2016. Retrieved from: https://lup.lub.lu.se/studentpapers/search/publication/8881325.

[36] Kourtellos, A. , Stengos, T. and Tan, C. M. THRET: Threshold Regression with Endogenous Threshold Variables. Discussion Paper: 03, Department of Economics, University of Cyprus. 2009.

[37] Hansen, B. E. Threshold effects in non-dynamic panels: Estimation, testing, and inference. Journal of Econometrics. 1999. 93(2): 345-368.

[38] Wang, Q. Y. Fixed-effect panel threshold model using Stata. The Stata Journal. 2015. 15(1): 121-134. 